\title{
Proportional-Integral-Derivative and Linear Quadratic Regulator Control of Direct Current Motor Position using Multi-Turn Based on LabView
}

\author{
Devi Handaya ${ }^{1}$, Resti Fauziah ${ }^{2}$ \\ ${ }^{1}$ Department of Mechanical Engineering, Jakarta State Polytechnic, Jakarta, Indonesia \\ ${ }^{2}$ Department of Electrical Engineering, Bandung Institute of Technology, Bandung, Indonesia \\ Email: devi.handaya@mesin.pnj.ac.id
}

\begin{abstract}
This study accommodates the industry needs in monitoring a control system on a DC motor using LabView. The servomotor, which is usually used for position control, was replaced in this study with a DC motor coupled with a multiturn potentiometer sensor. The use of DC motors was carried out to reduce actuator prices while maintaining control objectives. The control method used is in the form of Proportional - Integral - Derivative (PID) and optimal control which are then compared with the output. PID tuning is done using the Root Locus method. Meanwhile, for optimal control using the Linear Quadratic Regulation (LQR) approach. Testing was done by looking at the results of direct implementation of the DC motor plant hardware through observations using LabView. By using the right zero variables in the PID control, the best performance is obtained until it can track references. Too large a zero value will result in even greater Steady State Error. The results of optimal control using different $Q$ variables did not provide a significant change. The SSE value shows the same result. The results show that the optimal control can track the reference with lower settling time and overshoot than the PID control. However, the two control methods still produce relatively small Steady State Error.
\end{abstract}

Keywords-labview, monitoring system, position control, PID, optimal, LQR

\section{INTRODUCTION}

Actuator systems in the industry use a lot of electric motors which of course have several advantages compared to other types of actuators, especially the use of electric motors using linear control [1]. The use of electric motors in the industry is usually to control the speed of a system using the Proportional-Integral-Derivative (PID) control method [2], [3]. PID control is a control method commonly used in the industry. Besides PID, DC motors can also be controlled using optimal control [4][5][6][7][8]. The use of optimal control is intended to minimize energy use. Of course, the industry wants every process to have an efficiency value, especially in terms of energy use which has an impact on the efficiency of production costs.

For position control in systems in Industry, usually using servo motors [9][10][11]. The loads used in industry are usually very heavy, so they require a large servo torque [12]. In this research, researchers used a Direct Current (DC) motor to control its rotation position. The implementation of DC motors to control the rotation position [13][14][15][16] is done to replace servo motors which are relatively more expensive. Control on a DC motor, like a servo motor. The control method used is PID control and optimal control to compare the control results. Comparing the two control methods has been done [17] on speed control with the best results using optimal control. So the researcher wants to see the results obtained if the rotation position control is carried out. In addition to the control method, LabView is usually used to facilitate the process of observing and analyzing every physical phenomenon in the industry. This implementation has been carried out in monitoring DC motor position control using LabView [18][19].

\section{DESIGN OF LABVIEW MONITORING SYSTEM FOR DC MOTOR POSITION CONTROL}

\section{A. Front Panel of LabView Monitoring System}

Various measurement results from sensors can be displayed in LabView on the monitor using a Graphical User Interface (GUI) [20] and without contact with the plant [21]. The display design that can be directly observed by the observer can be seen in Fig. 1. This display shows a graph of the movement of the DC motor rotation position in both the real position and the reference position. The desired reference can be directly entered in the "Send Set Point". To select the desired type of control, it can be entered in "Control Mode".

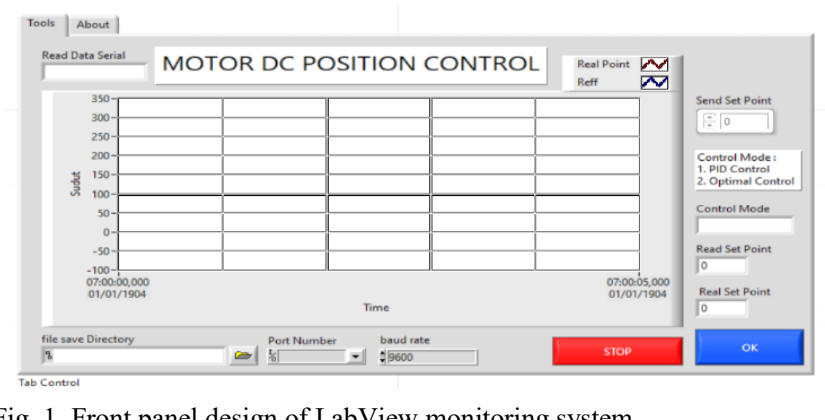

Fig. 1. Front panel design of LabView monitoring system 


\section{B. Block Diagram of LabView Monitoring System}

The block diagram design is a collection of block functions that are assembled to be used as a system flow in LabView. The advantage of this block diagram is in the form of a case structure, which is a function to determine the control method by the observer and any data obtained from the control system can be stored in a file save directory. The data acquisition system uses the Virtual Instrument Software Architecture (VISA) LabView protocol [22][23][24]. The following is a block diagram design.

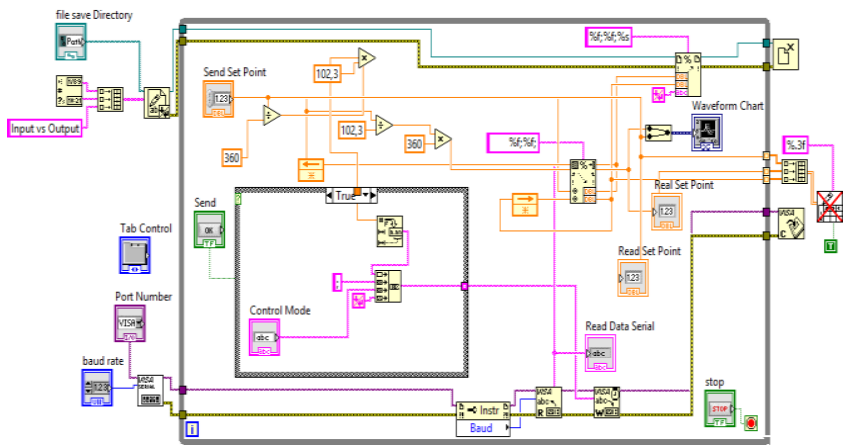

Fig. 2. Block diagram of Labview monitoring system

\section{DESIGN OF DC MOTOR POSITION CONTROL}

The design of the position control system on the DC motor is carried out based on the position of the DC motor rotation observed through LabView. The position sensor used in this study is a multi-turn or potentiometer with a total of 10 turns [25], [26]. Multi-turn is connected directly to the DC motor so that each rotation can be directly observed. Arduino Mega is used as a device controller that can achieve a reading of 10 bytes so that the digital data obtained will be more accurate.

The DC motor used in this study has been identified for the transfer function [18] using the Matlab Toolbox Identification System [27], [28] with the results in Fig. 3.

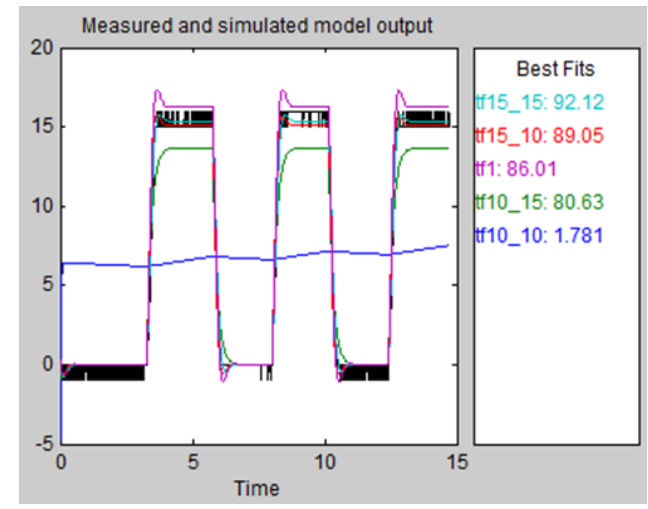

Fig. 3. Matlab Toolbox Identification System

Based on the identification system, best fits $92.12 \%$ were selected with the DC motor transfer function as follows.

$$
G(s)=\frac{83.54}{s^{2}+13.81 s+83.54}
$$

Based on the transfer function in equation (1), the design for determining the PID and Optimal control parameters should be started.

\section{A. PID Control Parameter Design}

The position control system on a DC motor with PID requires control parameters by tuning the PID. The PID tuning used in this study used the Root Locus method, this was done because other methods did not meet the criteria. The Root Locus method is a way to analyze the picture of the pole position shift in a closed-loop system from changes in open-loop gain [29]. Based on the transfer function (1), the desired pole result is $7.85 \pm 7.85$ i. From this pole, graphic mapping is made as Fig. 4.

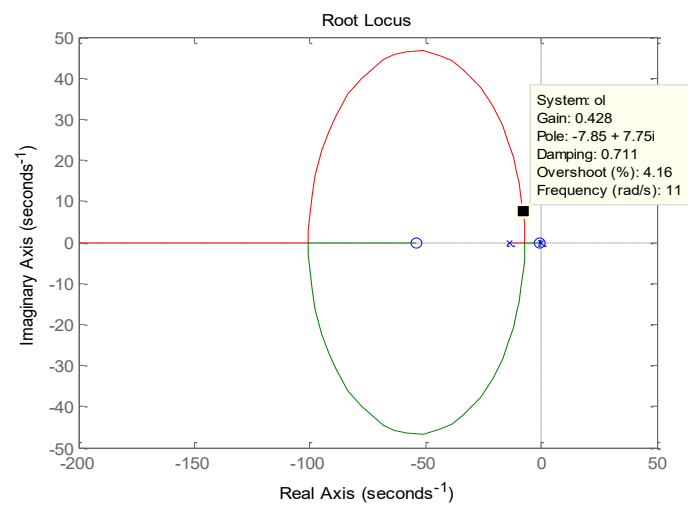

Fig. 4. The desired pole mapping graph of the DC motor transfer function

Based on Fig. 4., then the gain value from plotting Root Locus is 0.428 , the pole value is $-7.85 \pm 7.85 \mathrm{i}$, and zero 0.5 $\&$ 53.8857. Then the PID parameter search is carried out using the PID equivalent equation as follows.

$$
G_{c}(s)=\frac{K_{d} s^{2}+K_{p} s K_{i}}{s}=K_{d} s+K_{p}+\frac{K_{i}}{s}
$$

Based on Fig. 4 and the equivalence of equation (2), then the best parameter value is PID with $\mathrm{Kp}=23.617, \mathrm{Ki}=$ 11.6999 , and $\mathrm{Kd}=0.4343$.

\section{B. Optimal Control Parameter Design}

The optimization method for DC motors carried out in this study uses the Linear Quadratic Regulation (LQR), which is a method with the state space equation approach in linear systems by determining the $\mathrm{K}$ matrix from the optimal control vector [30], [31] in the following equation.

$$
u(t)=-K x(t)
$$

Through Equation (3), the system can reach a set point or reference. Then by minimizing the performance index using equation (4) as follows.

$$
J=\sum_{n=0}^{\infty}\left\{x^{T} Q x+u^{T} R u+2 x^{T} N u\right\}
$$

where $\mathrm{Q}$ is the real positive symmetric matrix and $\mathrm{R}$ is the positive definite real symmetric matrix, while $\mathrm{Nu}$ is obtained from the control signal $u$ in the following state space equation.

$$
\dot{x}=F x+G u, y=H x+J u
$$

$\dot{x}$ is the matrix derivative of the state vector $x, u$ is the input vector matrix, $u$ is the output vector matrix, $\mathrm{F}$ is the 
system matrix, $\mathrm{G}$ is the input matrix, $\mathrm{H}$ is the output matrix, and $\mathrm{J}$ is the feed-forward matrix.

Furthermore, the matrix $K_{L Q R}=\left[\begin{array}{ll}5 & 0.3389\end{array}\right]$ is included in the state feedback controller control design [32] according to the block diagram in Fig. 5.

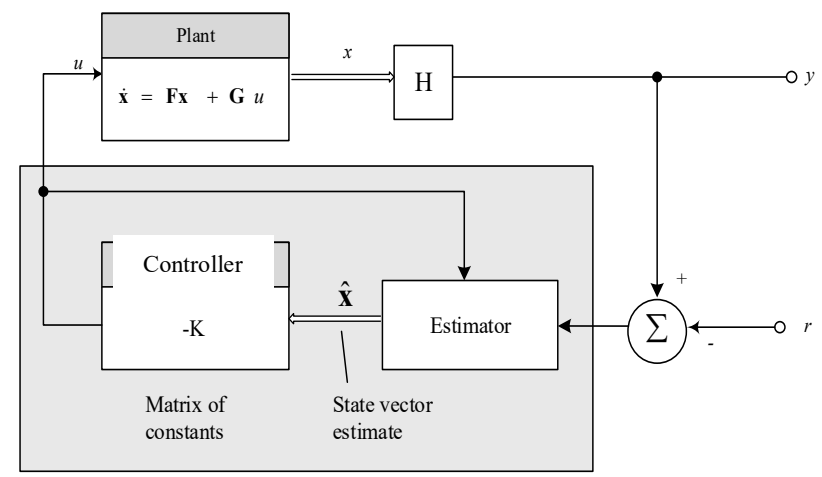

Fig. 5. State feedback controller diagram block

By using the principle according to the design Fig. 5., then the following equation transfer function (6) is obtained.

$$
D(s)=-K[S I A+B K+L C] L
$$

The use of an estimator is carried out to obtain all state variables because, in reality, not all state variables can be measured by the sensor. To get the estimator, it is necessary to look for the gain $\mathrm{L}$ value by placing the estimator poles of the desired dominant poles [32] and the $L=$ [48.9806; -230.8219] value is obtained. Matrix I is an identity matrix and matrices $\mathrm{A}, \mathrm{B}, \mathrm{C}$ is transformations between the forms of the matrix $\mathrm{F}, \mathrm{G}, \mathrm{H}$ which are used to determine the compensator $\mathrm{D}(\mathrm{s})$. The gain matrix $\mathrm{K}$ from both control methods is given to the state feedback controller to be able to track the reference.

\section{RESULT AND DISCUSSION}

Testing the position of the DC motor rotation in this study was carried out by directly implementing the DC motor plant. The results of the implementation of the plant are displayed on LabView as a monitoring system. Fig. 6 are the test results displayed on LabView.

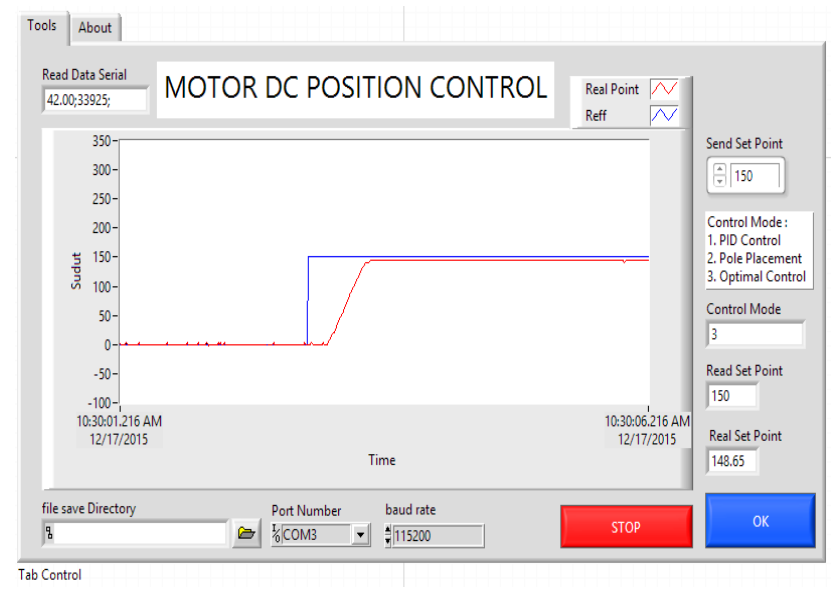

Fig. 6. Display of LabView monitoring system
On Fig. 6 shows that there is a graph in blue which is a control signal graph as a reference signal and the red graph is a graph of the sensor readings which is a real condition at the position of the DC motor. Reference the desired position of the DC motor at an angle of $150^{\circ}$, then the sensor readings show that the DC motor has succeeded in tracking in accordance with the desired position as well.

To clarify the reading results, it will be discussed according to the desired control method as follows.

\section{A. Tracking Position Control on DC Motor Using PID Control}

Position control testing on DC motor system hardware uses PID control which is tested at a position of $150^{\circ}$ with a certain zero value. Fig. 7 is resulting the graphical form and data.

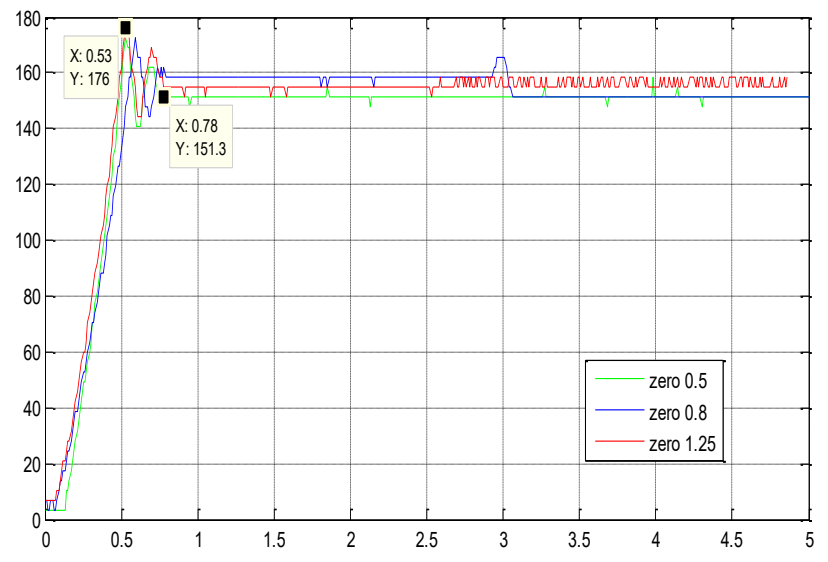

Fig. 7. Graph of the results of testing the position of a DC motor with PID control

Based on the test shown in Fig. 7 with the $\mathrm{X}$-axis as time and the $\mathrm{Y}$-axis as the angular position $\left({ }^{\circ}\right)$, the following data are obtained.

TABLE I. DATA OF POSITION TESTING RESULTS ON DC MOTOR PLANT WITH PID CONTROL

\begin{tabular}{|c|c|c|c|c|}
\hline Zero & $\begin{array}{c}\text { Settling } \\
\text { Time (s) }\end{array}$ & $\begin{array}{c}\text { Peak } \\
\text { Time (s) }\end{array}$ & Overshoot (\%) & Ess $\mathbf{(}^{\mathbf{}}$ ) \\
\hline 0.5 & 0.75 & 0.53 & 15 & 1.3 \\
\hline 0.8 & 3.1 & 0.58 & 17 & 1.3 \\
\hline 1.25 & 0.78 & 0.53 & 17 & 3 \\
\hline
\end{tabular}

Table I shows that testing using zero 0.5 produces the best performance with the fastest settling time. However, it still has a Steady State Error (SSE) of $1.3^{\circ}$. At zero 0.8 with the longest settling time also produces an SSE of $1.3^{\circ}$. Whereas at zero 1.25 it produces $3^{\circ}$, so it is not recommended to use a larger zero.

\section{B. Tracking Position Control on DC Motor Using Optimal Control}

The position control test on the DC motor system hardware uses optimal control to be entered in equation (5) at the $150^{\circ}$ position by varying the $\mathrm{R}$ values. Fig. 8 is resulting the graphical form and data. 


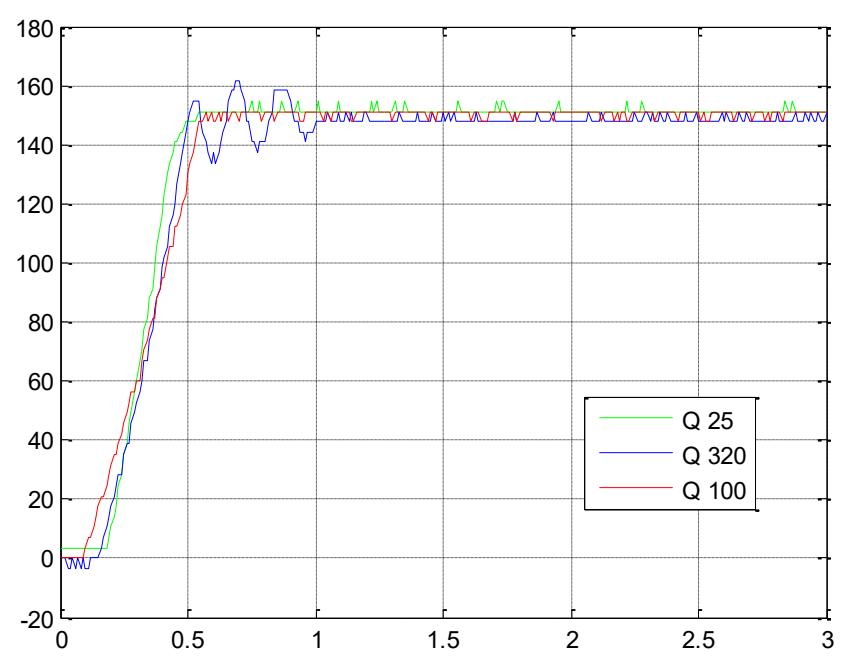

Fig. 8. Graph of the results of testing the position of the DC motor with optimal control

Based on the test shown in Fig. 8 with the $\mathrm{X}$-axis as time and the $\mathrm{Y}$-axis as the angular position $\left({ }^{\circ}\right)$, then the following data are obtained.

TABLE II. DATA OF POSITION TESTING RESULTS ON DC MOTOR PLANT WITH OPTIMAL CONTROL

\begin{tabular}{|c|c|c|c|c|}
\hline Q & $\begin{array}{c}\text { Settling } \\
\text { Time (s) }\end{array}$ & $\begin{array}{c}\text { Peak } \\
\text { Time (s) }\end{array}$ & Overshoot (\%) & Ess (') \\
\hline 25 & 0.5 & 0 & 0 & 1.3 \\
\hline 100 & 0.5 & 0 & 0 & 1.3 \\
\hline 320 & 0.8 & 0.75 & 6 & 1.3 \\
\hline
\end{tabular}

Based on the results shown in Table II, testing using $Q=25$ and $\mathrm{Q}=100$ values result in the same performance with the fastest settling time. While testing with a value of $Q=320$ results in settling time and overshoot. The test results of the three still have an SSE of $1.3^{\circ}$. With the difference in the range of $Q$ values that are quite far, it does not produce SSE that is too large, it just affects the settling time overshoot.

When compared to the best parameters based on the results of the tests presented in Tables I and II, it can be seen in the following comparison table.

TABLE III. COMPARISON OF POSITION TESTING RESULTS ON DC MOTOR PLANT WITH PID AND OPTIMAL CONTROL

\begin{tabular}{|c|c|c|c|}
\hline $\begin{array}{c}\text { Control } \\
\text { Method }\end{array}$ & $\begin{array}{c}\text { Settling } \\
\text { Time (s) }\end{array}$ & Overshoot (\%) & SSE ( $)$ \\
\hline PID & 0.75 & 15 & 1.3 \\
\hline Optimal & 0.5 & 0 & 1.3 \\
\hline
\end{tabular}

Based on the Table III, it can be seen that both have different settling times and overshoots. PID control requires a longer settling time of $0.25 \mathrm{~s}$ to be able to track references with an overshoot of $15 \%$. Compared to optimal control, settling time is faster and produces no overshoot. This is what the optimal control does, such as minimizing the settling time so that it does not produce overshoot. However, the two control methods both have an SSE of $1.3^{\circ}$. This error occurs, of course, comes from the nonlinearity factor of the multiturn sensor, but in reality, if you use a very capable sensor, the nonlinearity factor can be minimized so that the system can track references very well. This is proven based on validation with simulations using Matlab that there are no errors and the system can track references with settling time and overshoot according to the test results.

\section{CONCLUSION}

The DC motor rotation position control system has been successfully implemented using PID control and optimal with the LQR method approach. To be easily observed according to those used in the Industry using LabView. This is usually done in the Industry so that it can be observed in real-time. The value of the overshoot produced by the PID has quite a difference compared to the optimal control, this happens because the optimal control tries to minimize the energy used to track a reference. Likewise, the PID required settling time is greater because this control method still performs calculations, especially when summing the errors received from the multi-turn sensor. Both control methods have the same SSE value, this is because the multi-turn sensor has a nonlinearity condition. The nonlinearity factor is proven after validation using a simulation on Matlab which can track references, but the values of settling time and overshoot are the same as testing using hardware.

\section{REFERENCES}

[1] J. B. Wang, Control of Electric Machinery. Taiwan: Gau Lih. Book co., Ltd, 2001.

[2] K. K. Tan and S. Zhao, "Precision motion control with a high gain disturbance compensator for linear motors," ISA Trans., vol. 43, no. 3, pp. 399-412, 2004, doi: 10.1016/s0019-0578(07)60157-8.

[3] M. Ali, "Kontrol Kecepatan Motor DC Menggunakan PID Kontroler Yang Ditunning Dengan Firefly Algorithm," Intake J. Penelit. Ilmu Tek. Dan Terap., vol. 3, no. 2, pp. 1-10, 2012.

[4] R. M. K. Hummadi and A. Hummadi, "Simulation of Optimal Speed Control for a DC Motor Using Linear Quadratic Regulator," J. Eng., vol. 18 , no. 3, pp. 340-349, 2012.

[5] M. Khalilpour, H. H. Razmjooy, N., and P. Moallem, "Optimal Control of DC motor using Invasive Weed Optimization (IWO) Algorithm," Majlesi Conf. Electr. Eng., no. January, pp. 1-7, 2011.

[6] Y. Y. Hsu and W. C. Chan, "Optimal Variable-Structure Controller for Dc Motor Speed Control.," IEE Proc. D Control Theory Appl., vol. 131, no. 6 pt D, pp. 233-237, 1984, doi: 10.1049/ip-d.1984.0039.

[7] T. Abut, "Modeling and Optimal Control of a DC Motor," Int. J. Eng. Trends Technol., vol. 32, no. 3, pp. 146-150, 2016, doi: $10.14445 / 22315381 /$ ijett-v32p227.

[8] R. A. Michurin and A. Schagin, "Increase the accuracy of the DC motor control system with a linear-quadratic regulator," Proc. 2018 IEEE Conf. Russ. Young Res. Electr. Electron. Eng. ElConRus 2018, vol. 2018-Janua, no. 1, pp. 1746-1749, 2018, doi: 10.1109/EIConRus.2018.8317443.

[9] R. A. Osornio, "Identification of Positioning System for Industrial Applications using Neural Network," J. Sci. Ind. Res., vol. 76, no. 3, p. 144, 2017.

[10] H. Hou, X. Yu, L. Xu, K. Rsetam, and Z. Cao, "Finite-time continuous terminal sliding mode control of servo motor systems," IEEE Trans. Ind. Electron., vol. 67, no. 7, pp. 5647-5656, 2020, doi: 10.1109/TIE.2019.2931517.

[11] H. M. Flieh, R. D. Lorenz, E. Totoki, S. Yamaguchi, and Y. Nakamura, "Investigation of Different Servo Motor Designs for Servo Cycle Operations and Loss Minimizing Control Performance," IEEE Trans. Ind. Appl., vol. 54, no. 6, pp. 5791-5801, 2018, doi: 10.1109/TIA.2018.2849725.

[12] W. R. Y. A. Prasetya and I. W. Widhiada, "Implementasi Sistem Kontrol Fuzzy pada Robot Lengan Exoskeleton," J. METTEK, vol. 4, no. 2, p. 54, 2018, doi: 10.24843/mettek.2018.v04.i02.p04.

[13] D. Rawat, K. Bansal, and A. K. Pandey, LQR and PID design 
technique for an electric furnace temperature control system, vol. 479. 2017.

[14] A. Durdu and E. H. Dursun, "Sliding mode control for position tracking of servo system with a variable loaded DC motor," Elektron. ir Elektrotechnika, vol. 25, no. 4, pp. 8-16, 2019, doi: 10.5755/j01.eie.25.4.23964.

[15] M. E. F. Moran and N. A. P. Viera, "Comparative study for DC motor position controllers," 2017 IEEE 2nd Ecuador Tech. Chapters Meet. ETCM 2017, vol. 2017-Janua, pp. 1-6, 2018, doi: 10.1109/ETCM.2017.8247475.

[16] T. H. Mohamed, M. A. M. Alamin, and A. M. Hassan, "Adaptive position control of a cart moved by a DC motor using integral controller tuned by Jaya optimization with Balloon effect," Comput. Electr. Eng., vol. 87, no. September 2019, p. 106786, 2020, doi: 10.1016/j.compeleceng.2020.106786.

[17] A. Hashim and O. Ahmed, "Optimal Speed Control for Direct Current Motors Using Linear Quadratic Regulator," J. Sci. Technol. Engineering Comput. Sci., vol. 14, no. 2, pp. 48-56, 2013.

[18] D. Handaya, R. Fauziah, and T. Listyorini, "Real-time Monitoring System Using LabView for DC Motor Position Control Embedded System with PID and Pole Placement Control," pp. 375-381, 2019, doi: 10.4108/eai.24-10-2018.2280595.

[19] H. S. S. Siregar and R. M. S. Adinandra, "Model Predictive Control (MPC) untuk Sistem Motor DC Berbasis LabVIEW," Stud. Syst. Decis. Control, p. 18, 2018.

[20] T. Nagarjuna, K. Nehru, G. Nagendra Prasad, and N. Menakadevi, "Smart sensor network based high quality air pollution monitoring system using labview," Int. J. Online Eng., vol. 13, no. 8, pp. 79-87, 2017, doi: 10.3991/ijoe.v13i08.7161.

[21] R. M. Shrenika, S. S. Chikmath, A. V. Ravi Kumar, Y. V. Divyashree, and R. K. Swamy, "Non-contact Water Level Monitoring System Implemented Using LabVIEW and Arduino," Proc. - 2017 Int. Conf. Recent Adv. Electron. Commun. Technol. ICRAECT 2017, pp. 306309, 2017, doi: 10.1109/ICRAECT.2017.51.

[22] M. John, A. Joseph, and D. Vasanthi, "Design and implementation of low cost multichannel data acquisition hardware for computer aided measurement," Proc. - TIMA 2017 9th Int. Conf. Trends Ind. Meas. Autom., 2017, doi: 10.1109/TIMA.2017.8064805.
[23] P. M. Gavhane, D. S. Sutrave, V. D. Bachuwar, S. D. Gothe, and P. S. Joshi, "Smart Turbidity Monitoring and Data Acquisition using LabVIEW," J. Xidian Univ., vol. 14, no. 5, pp. 22-30, 2020, doi: $10.37896 /$ jxu14.5/290

[24] E. A. El-Behiry, E. S. S. Ahmed, and T. Mahmoud, "Real-Time Wireless Control for a Data Acquisition-Based Micro-Computer System," J. Electron. Mater., vol. 48, no. 8, pp. 4762-4772, 2019, doi: 10.1007/s11664-019-07324-1.

[25] W. P. S. Freitas, C. R. Cena, D. C. B. Alves, and A. M. B. Goncalves, "Arduino-based experiment demonstrating Malus's law," Phys. Educ., vol. 53, no. 3, 2018, doi: 10.1088/1361-6552/aab43d.

[26] D. Parras-Burgos, A. Gea-Martínez, L. Roca-Nieto, D. G. FernándezPacheco, and F. J. F. Cañavate, "Prototype system for measuring and analyzing movements of the upper limb for the detection of occupational hazards," Sensors (Switzerland), vol. 20, no. 17, pp. 117, 2020, doi: 10.3390/s20174993.

[27] Y. Naung, A. Schagin, H. L. Oo, K. Z. Ye, and Z. M. Khaing, "Implementation of Data Driven Control System of.pdf," pp. 18011804, 2018.

[28] A. Arda Ozdemir and S. Gumussoy, "Transfer Function Estimation in System Identification Toolbox via Vector Fitting," IFACPapersOnLine, vol. 50, no. 1, pp. 6232-6237, 2017, doi: 10.1016/j.ifacol.2017.08.1026.

[29] Q. G. Wang, T. H. Lee, H. W. Fung, Q. Bi, and Y. Zhang, "PID tuning for improved performance," IEEE Trans. Control Syst. Technol., vol. 7, no. 4, pp. 457-465, 1999, doi: 10.1109/87.772161.

[30] U. Badri, Kontrol Optimal Pada Motor DC Menggunakan Metode Linear Quadratic Regulator. Surabaya: ITS, 2012.

[31] Ilham, "Kendali Linear Quadratic Regulator ( LQR ) Pada Motor Induksi 3 Phasa dengan Direct Torque Control ( DTC )," J. Teknol. Inf. dan Komun., vol. 4, no. 2, pp. 45-52, 2014.

[32] G. F. Franklin, D. J. Powell, and A. Emami, Feedback Control of Dynamic Systems, 6th ed., vol. 6, no. 3. London: Pearson Education Ltd., 2010. 